\title{
Managements for Obstructive Sleep Apnea in Adults: Review
} Gantuya Tserenpil ${ }^{1}$, Meklit Gebre ${ }^{1}$, Azka Shahid Zergham ${ }^{1}$, Amanpreet Kaur Sekhon ${ }^{1}$, Bilal Haider Malik

1. Internal Medicine, California Institute of Behavioral Neurosciences \& Psychology, Fairfield, USA

Corresponding author: Gantuya Tserenpil, gantuya.tsl@gmail.com

\begin{abstract}
Obstructive sleep apnea (OSA) is characterized by recurrent obstruction of the pharyngeal airway during sleep, with resultant hypoxia and sleep fragmentation. It is more common in middle-aged obese men and prevalence is higher in most obese people. However, prevalence is high in African-Americans. OSA is associated with major comorbidities including excessive daytime sleepiness and increased risk of cardiovascular diseases. First and foremost, OSA management starts from educating patients about shortterm consequences like motor vehicle accidents, behavioral modifications, long term consequences like cardiopulmonary disease, and resistant high blood pressure. Various types of management options are available for OSA such as weight loss, CPAP, oral appliances, and surgery. The review aims to explain the pathophysiology and cause of the obstruction of the airway in order to choose proper management carefully to decrease the symptoms and cure the disease.
\end{abstract}

Categories: Internal Medicine, Quality Improvement

Keywords: obstructive sleep apnea, sleep disturbance, cpap, oral appliance

\section{Introduction And Background}

Obstructive sleep apnea (OSA) is characterized by episodes of a partial or complete collapse of the upper or lower airway during sleep, resulting in nocturnal hypoxemia [1]. The pathogenesis of OSA is due to the interaction between unfavorable anatomic upper airway (UA) susceptibility and sleep-related changes in UA function [2]. OSA causes excessive daytime sleepiness, negatively affects quality of life, and increases the risk of cardiopulmonary disease, hypertension, and metabolic syndrome [3]. The disease severity is measured using the apnea-hypoxia index (AHI), i.e. the mean number of apneas and hypopneas per hour sleep.

OSA is more common in the middle-aged population with an increased prevalence of obesity [4]. OSA has a significant negative effect on the quality of life and function of the organs and systems, including increased risk of cardiovascular disease, high blood pressure, sexual dysfunction, daytime somnolence, and even sudden death. The other potential consequences of OSA include excessive daytime sleepiness, impaired daytime function, exacerbation of metabolic abnormalities (e.g., impaired glucose tolerance, insulin resistance, type 2 diabetes mellitus, dyslipidemia), and an increased risk of chronic kidney disease and mortality. Several of these conditions appear to have a bidirectional risk association with OSA, including type 2 diabetes mellitus, chronic kidney disease, and left ventricular heart failure [5]. It is also known to be associated with an increased risk of postoperative complications [6].

() Copyright 2020

Tserenpil et al. This is an open access article distributed under the terms of the Creative Commons Attribution License CC-BY 4.0., which permits unrestricted use, distribution, and reproduction in any medium, provided the original author and source are credited.
There are many treatment options to relieve the symptoms and prevent apnea episodes during the night. One of the most important parts of controlling OSA symptoms and maybe a cure is to educate the patient about the risks, consequences, and diet and exercise. Importantly, all patients should be warned about the increased risk of motor vehicle accidents associated with untreated OSA and the potential consequences of driving or operating other dangerous equipment while sleepy. Patients should also be counseled to avoid activities that require vigilance and alertness if sleepy [2]. In addition, continuous positive airway pressure is another effective treatment [7]. There are three major positive airway pressure (PAP) modalities used to treat patients with OSA: continuous positive airway pressure (CPAP), bilevel positive airway pressure (BPAP), and automatic positive airway pressure (APAP). CPAP is generally preferred for most patients because it has been well studied, is simpler to use, and is less costly [5]. Epidemiology, pathophysiology, and treatment options for OSA are reviewed here. The aim of the report is to explore OSA and treatment options that improve the airway and prevent further systemic complications of OSA.

\section{Review}

\section{Prevalence of obstructive sleep apnea (OSA)}

Obstructive sleep apnea (OSA) is characterized by episodes of a partial or complete collapse of the upper airway during sleep resulting in nocturnal hypoxemia, a prevalence estimated at $14 \%-49 \%$ in the USA and Europe [8]. Epidemiological studies between 1993 and 2013 show that OSA occurs in 6\% of men and in $4 \%$ of 
women in prevalence [1]. However, it is more common in older, obese, males. The prevalence of OSA is common in obese people with Body Mass Index $(\mathrm{BMI})>30$ and even higher in patients with a BMI $>40$. The race varies in OSA but there is a slightly increased prevalence in African-Americans [9].

\section{Pathophysiology of OSA}

Although the precise pathophysiology of OSA is not well understood, it is believed that the changes in the upper airway mechanics, ventilatory motor output, surrounding tissue structure, and expiratory narrowing triggers the pharyngeal obstruction during sleep in susceptible individuals. Upper airway mechanics - The complete closure of the deformable upper airway due to collapsing transmural pressure during sleep leads to a pathologic increase in the partial pressure of carbon dioxide (PaCO2) in OSA [10]. Ventilatory motor output - changes in the ventilatory drive, including the ventilatory motor output fluctuation during periodic breathing, result in upper airway narrowing and obstruction $[3,11,12]$. Surrounding tissue - upper airway patency is affected by the passive gravitational forces and high tissue pressure in individuals with mandibular deficiency, large tongue size, fat accumulated in the upper airway, or pharyngeal wall edema secondary to rostral fluid shifts in the recumbent position [13]. Expiratory narrowing - OSA is preceded by expiratory narrowing of the upper airway with increased expiratory resistance or progressive expiratory narrowing [14]. During sleep, there is physiologic hypercapnia ( $\mathrm{PaCO} 2$ rise by $4-5 \mathrm{mmHg}$ ) due to a combination of increased upper airway resistance and decreased ventilatory motor output [15]. The patients with OSA, however, develop considerable hypercapnia and hypoxia due to complete obstruction of the upper airway [1]. OSA is therefore associated with consequences including hypertension, pulmonary hypertension, neurocognitive effects, depressed quality of life, motor vehicle accidents, awakening headache, childhood growth interruption, pregnancy-induced hypertension, fetal growth retardation, and disruption of the patients' bed-partners' sleep quality [16].

\section{Managements of OSA}

OSA has many different treatment options in order to improve the quality of sleep, eliminate apnea episodes, and increase oxygen saturation during the night [17]. While behavioral modification, CPAP, and oral appliance require long term management, surgery can be done and improve apnea symptoms in days [18]. Effective treatment will reduce many consequences of OSA, such as motor vehicle accidents, cardiovascular mortality, and morbidity. In this section, varies of the managements of OSA will be discussed.

Education and Behavioral Change

Education is one of the utmost important parts of the treatment in patients with OSA. Patients with OSA should be educated about the risks, health consequences, and treatment compliance. Increased risks of motor vehicle accidents are prevalent in patients with OSA. Patients with OSA are 2.5 times more likely to have car accidents due to daytime sleepiness. Patients should be advised to avoid duties such as driving, attentiveness, and surveillance while feeling sleepy. Many behavioral modifications can be combined with treatments such as weight loss, sleeping position, and avoidance of some medications and substances. Obesity is the main risk factor for OSA. In a study of 2148 people with BMI $>30,50 \%$ had milder OSA, and $25 \%$ showed severe OSA. Prevalence is even higher and reaches $98 \%$ in patients with BMI >40 [4,19].

In most cases, weight loss improves the symptoms and cures OSA. Unfortunately, in some cases, weight loss does not bring positive results. However, it is important to modify diet and exercise on a daily basis for patients with OSA $[6,20]$. Sleeping position is another behavioral change that patients with OSA need to take [21]. Sleeping on the back causes the tongue to relax further to the throat and blocks the airway [22]. Sleeping on the side makes the less obstruction in some patients. Most of the treatments of OSA require long term management that requires daily commitment, so educating patients about the importance of adherence to the treatment is the key to a successful outcome of the treatment and avoids possible negative health consequences [23]. Patients also are encouraged to abstain from alcohol, substance, and some medications such as benzodiazepines. They depress the central nervous system and worsen the drowsiness during the day $[2]$.

Continuous Positive Airway Pressure Therapy

CPAP is one of the most effective therapies used in OSA that opens the airway by delivering the airway through the tube and prevents air collapse during sleep. Positive airway pressure therapy is highly efficacious in reducing car accidents, improving the quality of sleep, reducing blood pressure, and preventing cardiovascular disease development due to OSA [24]. In a meta-analysis of 35 trials, CPAP showed positive results in the apnea-hypopnea index (AHI) mean difference - 33.8 events in an hour. However, 10-year randomized trial evidence shows that there is no significant reduction in cardiovascular events [7]. CPAP also decreases the periodic limb movement in mild OSA patients [25]. In another study, CPAP id not directly lower blood pressure and had less effect on it [4,9].

We ran a total of four different trials using the meta-analysis (Table 1) [7-26]. 


\section{Cureus}

\begin{tabular}{|c|c|c|}
\hline Trials & Purpose & Result \\
\hline 35 & reduction in the apnea-hypopnea index & Improved \\
\hline 22 & sleepiness, quality of life, cognitive function, and depression & Improved \\
\hline 35 & mortality & None \\
\hline 23 & motor vehicle crashes & Improved \\
\hline
\end{tabular}

\section{TABLE 1: Meta-Analysis of CPAP therapy outcome}

CPAP: continuous positive airway pressure

Choosing the right device is as important as adherence to the daily usage of CPAP. There are three ways of administering the positive airway pressure therapy: continuous positive airway pressure (CPAP), bilevel positive airway pressure (BPAP), and automatic positive airway pressure (APAP) [5,27,28-29].

In Table 2, we discuss different types of positive airway pressure options that can be utilized in OSA management.

\begin{tabular}{|l|l|l|}
\hline Modes & Descriptions & Recommendation \\
$\begin{array}{l}\text { Continuous Positive Airway } \\
\text { Pressure (CPAP) }\end{array}$ & $\begin{array}{l}\text { Delivers continuous pressure throughout the } \\
\text { respiratory cycle }\end{array}$ & $\begin{array}{l}\text { Mild to moderate sleep apnea, and may benefit cardiogenic } \\
\text { and pulmonary edema }\end{array}$ \\
$\begin{array}{l}\text { Bilevel Positive Airway Pressure } \\
\text { (BiPAP) }\end{array}$ & $\begin{array}{l}\text { Presents inspiratory and expiratory airway } \\
\text { pressure }\end{array}$ & $\begin{array}{l}\text { Acute hypercapnia, immunosuppressed individuals with } \\
\text { infection }\end{array}$ \\
$\begin{array}{l}\text { Auto-adjusting airway pressure } \\
\text { (APAP) }\end{array}$ & $\begin{array}{l}\text { Works via algorithmic control in response to } \\
\text { airflow change }\end{array}$ & Rem-related apnea, and positional apnea \\
\hline
\end{tabular}

\section{TABLE 2: Continuous airway pressure types}

CPAP: continuous positive airway pressure, BPAP: bilevel positive airway pressure, APAP: automatic positive airway pressure

Studies shows that using CPAP for at least four hours a day significantly reduces chronic inflammation and improves daytime sleepiness [27-30].

Oral Appliance

The second most common therapy for OSA is mandibular advancement devices. Two main oral appliances are mandibular advancement splints (MAS) and tongue retaining devices [31]. People may prefer oral appliances over CPAP as they are more comfortable. However, apart from the convenience, oral appliances are proven to be less effective than CPAP, especially in severe OSA. In short-term benefits, MAS reduces the arousal and apnea-hypopnea index [30]. It also improves oxyhemoglobin saturation and snoring. In a study of 10 years follow-up of patients with OSA, MAS presents mean AHI was $31.7 \pm 20.6$, whereas in the CPAP group 49.2 \pm 26.1 in mild to moderate cases [16]. However, MAS shows inconsistent results in terms of complete resolution of OSA and subjective daytime sleepiness improvement [17].

Surgery

Surgery for OSA is the last resort treatment [20]. CPAP or oral devices should be tried first. Surgery can be used to eliminate airway obstruction and remove excess tissue from the upper airway without impairing normal functions of the structures to widen the upper airway space [21]. Surgery is recommended in patients with severe OSA (AHI is $<20 / \mathrm{h}$ ), failure of CPAP and other OSA managements, and anatomical location causing obstruction [27]. Contraindications to surgery include patients with dysphagia, morbid obesity, nasopharyngeal reflux, and unstable cardiopulmonary conditions [32]. Many surgical methods can be used to open the airway space for OSA patients, and it is important to evaluate the patients for appropriate surgical procedures to reach the maximum benefit [29-33,34].

In Table 3, we discuss different managements that can be utilized to improve the airway for patients with 


\section{Cureus}

OSA $[5,9,26-29,30,32]$.

\begin{tabular}{|c|c|c|}
\hline Methods & Descriptions & Efficacy in OSA \\
\hline \multicolumn{3}{|l|}{ Nasal procedures } \\
\hline Rhinoplasty & $\begin{array}{l}\text { Correct other anatomic nasal airway } \\
\text { abnormalities }\end{array}$ & $\begin{array}{l}\text { In case of trauma, narrow bony aperture, or abnormalities that } \\
\text { cause blockage of the airway. }\end{array}$ \\
\hline Turbinate reduction & $\begin{array}{l}\text { Reduce inferior turbinate to reduce airway } \\
\text { obstruction }\end{array}$ & In the turbinate hypertrophy cases, it improves the airway. \\
\hline Nasal valve surgery & $\begin{array}{l}\text { Opens the collapsed valves to increase airway } \\
\text { space }\end{array}$ & \\
\hline Septoplasty & Strengthens the nasal septum & $\begin{array}{l}\text { An only mild case of Obstructive Sleep Apnea (OSA) with curved } \\
\text { nasal septum }\end{array}$ \\
\hline \multicolumn{3}{|l|}{ Upper airway procedures } \\
\hline Uvulopalatopharyngoplasty & $\begin{array}{l}\text { Remove the excess tissue from soft palate, } \\
\text { pharynx, and uvula }\end{array}$ & $\begin{array}{l}\geq 50 \text { percent reduction in the apnea-hypopnea index }(A H I) \text { and a } \\
\text { postsurgery } A H I<20 \text { events per hour }\end{array}$ \\
\hline Tonsillectomy & Removes tonsil tissue & 216 adult study shows $65 \%$ of the $\mathrm{AHI}$ mean improvement \\
\hline \multicolumn{3}{|l|}{ Lower airway procedures } \\
\hline $\begin{array}{l}\text { Radiofrequency tongue } \\
\text { reduction }\end{array}$ & Reduces tongue tissue & \\
\hline Midline glossectomy & $\begin{array}{l}\text { Widens the space of hypopharyngeal airspace } \\
\text { via carbon dioxide laser }\end{array}$ & the success rate of $60 \%$ reducing $\mathrm{AHI}$ \\
\hline Lingualplasty & Submucosal tongue reduction & In a study, $\mathrm{AHI}$ is decreased from $44.0 \pm 4.3$ to $12.5 \pm 2.3$. \\
\hline \multicolumn{3}{|l|}{$\begin{array}{l}\text { Global upper airway } \\
\text { procedures }\end{array}$} \\
\hline $\begin{array}{l}\text { Maxillomandibular } \\
\text { advancement }\end{array}$ & Reposition the upper and lower jaw & $\begin{array}{l}21 \text { patients of meta-analysis, it shows an improvement of } 86 \% \text { in } \\
\text { AHI }\end{array}$ \\
\hline
\end{tabular}

TABLE 3: Different types of surgical options for OSA

OSA: obstructive sleep apnea, AHI: apnea-hypoxia index

\section{Conclusions}

In this review article, possible management of OSA and outcomes are discussed in detail. Many articles associated with OSA management, pathophysiology, prevalence, outcomes of the treatments are summarized and reviewed here. One of the most important parts of controlling OSA symptoms and maybe a cure is to educate the patient about the risks, consequences, and diet and exercise. CPAP is one of the promising treatments if the patient is compliant with the daily regime. The second efficient therapy is oral devices because of their convenience to use over CPAP. Finally, we discussed various surgical procedures that can be done in OSA if other managements are not efficient. Understanding the pathogenesis of the OSA and choosing the right treatment depends on the cause of obstruction, and it is the key to a successful outcome of the management.

\section{Additional Information}

\section{Disclosures}

Conflicts of interest: In compliance with the ICMJE uniform disclosure form, all authors declare the following: Payment/services info: All authors have declared that no financial support was received from any organization for the submitted work. Financial relationships: All authors have declared that they have no financial relationships at present or within the previous three years with any organizations that might have an interest in the submitted work. Other relationships: All authors have declared that there are no other relationships or activities that could appear to have influenced the submitted work. 


\section{References}

1. Eckert DJ, Malhotra A: Pathophysiology of adult obstructive sleep apnea. Proc Am Thorac Soc. 2008, 5:144153. 10.1513/pats.200707-114MG

2. Management of obstructive sleep apnea in adults. (2019). Accessed: 2019: https://www.uptodate.com/contents/management-of-obstructive-sleep-apnea-in-adults .

3. Pathophysiology of obstructive sleep apnea in adults . (2019). Accessed: 2019: http://www.uptodate.com/contents/pathophysiology-of-obstructive-sleep-apnea-in-adults

4. Garcia JM, Sharafkhaneh H, Hirshkowits M, et al.: Weight and metabolic effects of CPAP in obstructive sleep apnea patients with obesity. Respir Res. 2019, 12:80. 10.1186/1465-9921-12-80

5. Initiation of positive airway pressure therapy for obstructive sleep apnea in adults . (2019). Accessed: 2019 http://www.uptodate.com/contents/initiation-of-positive-airway-pressure-therapy-for-obstructive-sleepapnea-in-adults.

6. Mutter TC, Chateau D, Moffatt M, et al.: A matched cohort study of postoperative outcomes in obstructive sleep apnea: could preoperative diagnosis and treatment prevent complications. Anesthesiology. 2014, 121:707. 10.1097/ALN.0000000000000407

7. Christine $\mathrm{P}$, Sorcha A, James $\mathrm{P}$, et al.: The efficacy of continuous positive airway pressure therapy in reducing cardiovascular events in obstructive sleep apnea: a systematic review. Future Cardiol. 2017, 13:397-412. 10.2217/fca-2017-0004

8. Peppard PE, Young T, Barnet JH, et al.: Increased prevalence of sleep-disordered breathing in adults . Am J Epidemiol. 2013, 177:1006. 10.1093/aje/kws342

9. Redline S, Tishler PV, Hans MG, et al.: Racial differences in sleep-disordered breathing in AfricanAmericans and Caucasians. Am J Resp Crit Care Med. 1997, 155:186. 10.1164/ajrccm.155.1.9001310

10. Sankri-Tarbichi AG, Rowley JA, Badr MS: Expiratory pharyngeal narrowing during central hypocapnic hypopnea. Am J Resp Crit Care Med. 2009, 179:313. 10.1164/rccm.200805-7410C

11. Dempsey JA, Veasey SC, Morgan BJ, et al.: Pathophysiology of sleep apnea. Physiol Rev. 2010, 90:47. 10.1152/physrev.00043.2008

12. Orem J, Lovering AT, Dunin-Bakowski W, Vidruk EH: Tonic activity in the respiratory system in wakefullness, NREM and REM. Sleep. 2002, 25:488. 10.1152/physrev.00043.2008.

13. Khoo MC: Determinants of ventilatory instability and variability . Respir Physiol. 2000, 122:167. 10.1016/s0034-5687(00)00157-2

14. Sforza E, Bacon $\mathrm{W}$, Weiss $\mathrm{T}$, et al.: Upper airway collapsibility and cephalometric variables in patients with obstructive sleep apnea. Am J Resp Crit Care Med. 2000, 161:347. 10.1164/ajrccm.161.2.9810091

15. Newman AB, Foster G, Givelber R, et al.: Progression and regression of sleep-disordered breathing with changes in weight: the sleep heart health study. Arch Intern Med. 2005, 165:2408. 10.1001/archinte.165.20.2408

16. Susan M. Harding, MD: Complications and consequences of obstructive sleep apnea . Curr Opin Pulm Med. 2000, 1070:5287. 10.1097/00063198-200011000-00004

17. Ballard RD. Gay PC, Strollo PJ: Interventions to improve compliance in sleep apnea patients previously noncompliant with continuous positive airway pressure. J Clin Sleep Med. 2007, 3:706. 10.1097/00063198200011000-00004

18. Qaseem A, Holty JE, Owens DK, et al.: Management of obstructive sleep apnea in adults: a clinical practice guideline from the American College of Physicians. Ann Intern Med. 2013, 24061345:159-471. 10.7326/0003-4819-159-7-201310010-00704

19. Epstein LJ, Kristo D, Strollo PJ Jr, et al.: Clinical guideline for the evaluation, management and long term care of obstructive sleep apnea in adults. J Clin Sleep Med. 2009, 5:263.

20. Raveendran R, Wong J, Singh M, et al.: Obesity hypoventilation syndrome, sleep apnea, overlap syndrome: perioperative management to prevent complications. Curr Opin Anaesthesiol. 2017, 30:146. 10.1097/ACO.0000000000000421

21. Frey WC, Pilcher J: Obstructive sleep-related breathing disorders in patients evaluated for bariatric surgery . Obes Surg. 2003, 13:676. 10.1381/096089203322509228

22. Szollosi I, Roebuck T, Thompson B, Naughton MT: Lateral sleeping position reduces severity of central sleep apnea/Cheyne-Stokes respiration. Sleep. 2006, 29:1045. 10.1093/sleep/29.8.1045

23. Araghi MH, Chen YF, Jagielski A, et al.: Effectiveness of lifestyle interventions on obstructive sleep apnea: a systematic review and meta-analysis. Sleep. 2013, 36:1553. 10.5665/sleep.3056

24. Tarraubella N, Sanchez-de-la-Torre M, Nadal N, et al.: Management of obstructive sleep apnea in primary care vs sleep unit setting: a randomised controlled trial. Thorax. 2018, 73:1152. 10.1136/thoraxjnl-2017211237

25. Baran AS, Richert AC, Douglass AB, May W, Ansarin K: Change in periodic limb movement index during treatment of obstructive sleep apnea with continuous positive airway pressure. Sleep. 2003, 98:1570-1573. 10.1093/Sleep/26.6.717

26. Kunisaki KM, Greer N, Khalil W, et al.: Provider types and outcomes in obstructive sleep apnea case finding and treatment: a systematic review. Ann Intern Med. 2018, 168:195. 10.7326/M17-2511

27. Fujita S, Woodson BT, Clark JL, et al.: Laser midline glossectomy as a treatment for obstructive sleep apnea . 1991. 10.1288/00005537-199108000-00001

28. De Vries GE, Hoekema A, Doff MH, et al.: Usage of positional therapy in adults with obstructive sleep apnea . J Chin Med. 2015, 11:131. 10.5664/jcsm.4458

29. Surgical risk and the preoperative evaluation and management of adults with obstructive sleep apnea . (2019). Accessed: 2019: https://www.uptodate.com/contents/surgical-risk-and-the-preoperativeevaluation-and-management-of-adults-with-obstruc....

30. Kairaitis K, Stavrinou R, Parikh R, et al.: Mandibular advancement decreases pressures in the tissues surrounding the upper airway in rabbits. J Appl Physiol. 2006, 100:349. 10.1152/japplphysiol.00560.2005

31. Kasai T, Bradley TD, Friedman O, Logan AG: Effect of intensified diuretic therapy on overnight rostral fluid shift and obstructive sleep apnea in patients with uncontrolled hypertension. J Hypertens. 2014, 32:673. 


\section{Cureus}

10.1097/HJH.0000000000000047

32. Banu SA, Tulin T: Long-term obstructive sleep apnea therapy; a 10-year follow-up of mandibular advancement device and continuous positive airway pressure. J Clin Sleep Med. 2018, 10.5664/jcsm.8204

33. Bakker JP, Marshall NS: Flexible pressure delivery modification of continuous positive airway pressure for obstructive sleep apnea does not improve compliance with therapy: Systemic review and meta-analysis. Chest. 2011, 139:1322. 10.1378/chest.10-2379

34. Fernandez BA, Bartels K, Clavijo C, et al.: Preoperatively screened obstructive sleep apnea is associated with worse postoperative outcomes than previously diagnosed obstructive sleep apnea. Anesthesiology. 2017, 125:593. 10.1213/ANE.0000000000002241 